\title{
Radiological findings and endovascular treatment in giant deep femoral artery aneurysms
}

\author{
Suat Keskin, ${ }^{1}$ Osman Koc, ${ }^{1}$ Zeynep Keskin, ${ }^{2}$ Seyit Erol ${ }^{1}$
}

${ }^{1}$ Department of Radiology, Necmettin Erbakan University, Meram School of Medicine, Konya, Turkey

${ }^{2}$ Department of Radiology, Konya Training and Research Hospital, Konya, Turkey

\section{Correspondence to}

Dr Suat Keskin

drsuatkeskin@yahoo.com

Accepted 13 November 2014

\section{DESCRIPTION}

An 81-year-old man presented to the cardiovascular surgery clinic with right inguinal pain and swelling, which he had experienced for 1 year. A pulsatile mass that extended to the proximal femur was found in the right of the groin on physical examination. There was no sign of limb-threatening ischaemia. Blood urea nitrogen was $54 \mathrm{mg} / \mathrm{dL}$ and glucose was $168 \mathrm{mg} / \mathrm{dL}$. The patient had unstable cardiac function. Superficial ultrasound showed an approximately $9 \mathrm{~cm}$ hypodense cystic lesion. Colour Doppler ultrasound (figure 1) showed that the lesion was connected to the deep femoral artery. Thrombosis was seen in the aneurysm. Additionally, deep vein thrombosis was found in the right superficial femoral vein extending to the knee. There was no flow on Power Doppler examination. Atherosclerotic intimal hyperplasia and enlargement were seen in the orifice of the superficial femoral artery. Contrast-enhanced MR angiography (figure 2) revealed a $10 \mathrm{~cm}$ giant aneurysm that was connected to the deep femoral artery (DFA) in the right of the groin. A $5.5 \mathrm{~cm}$ thrombosis was seen on the anterior wall of the aneurysm. The patient underwent conventional angiography for treatment. On angiography (figure 3), a giant aneurysm originating in the DFA was seen. Vascular continuity was established on the distal portion of the aneurysm. The distal embolisation was executed with a peripheral microcatheter. Proximal embolisation was attempted with microcatheter retraction. Peripheral coils were placed on the neck of the aneurysm. Subsequently, no blood filling was seen in the lumen of the aneurysm (figure 4).

Aneurysms of the DFA are rare clinical entities. ${ }^{1}$ They occur in elderly men. Patients with aneurysms

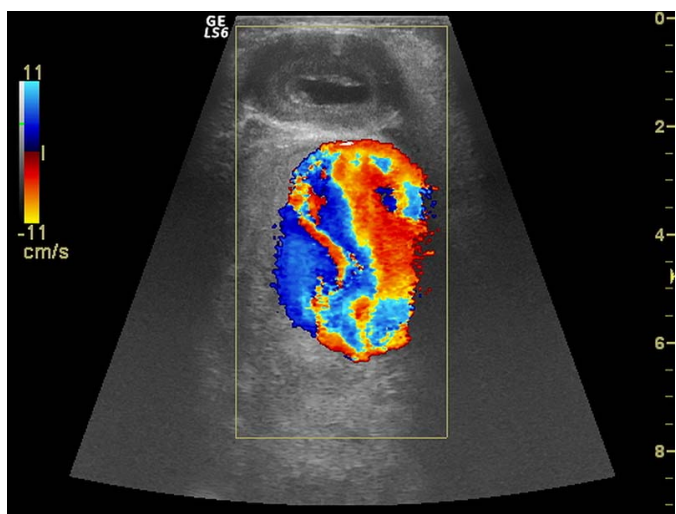

To cite: Keskin $\mathrm{S}, \mathrm{Koc} \mathrm{O}_{1}$ Keskin Z, et al. BMJ Case Rep Published online: [please include Day Month Year] doi:10.1136/bcr-2013201201
CrossMark

Figure 1 Colour Doppler ultrasound showing a giant deep femoral artery aneurysm with yin-yang appearance, measuring approximately $9 \mathrm{~cm}$. The enlargement and intimal thickness in the main femoral artery is seen at anterior of the aneurysm.

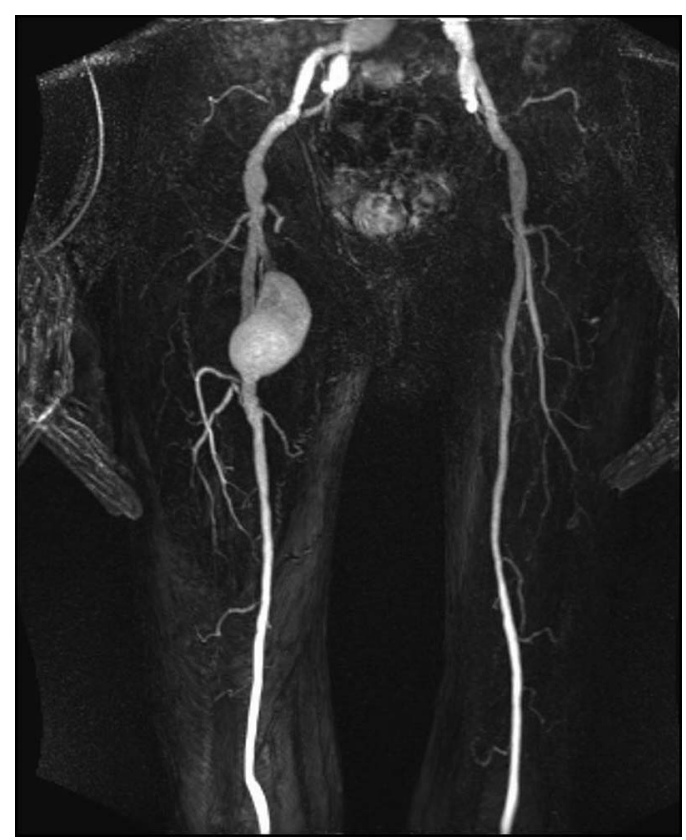

Figure 2 Contrast-enhanced MR angiography showing a giant deep femoral artery aneurysm in the right of the groin.

present with ischaemic symptoms. Usually, patients with aneurysms have peripheral atherosclerotic disease. ${ }^{2}$ Distal venous stasis and thrombosis related to local venous compressions are other possible complications. In our patient, thrombosis was found in the superficial femoral vein. Ultrasound, CT-MR and conventional angiography may be useful for

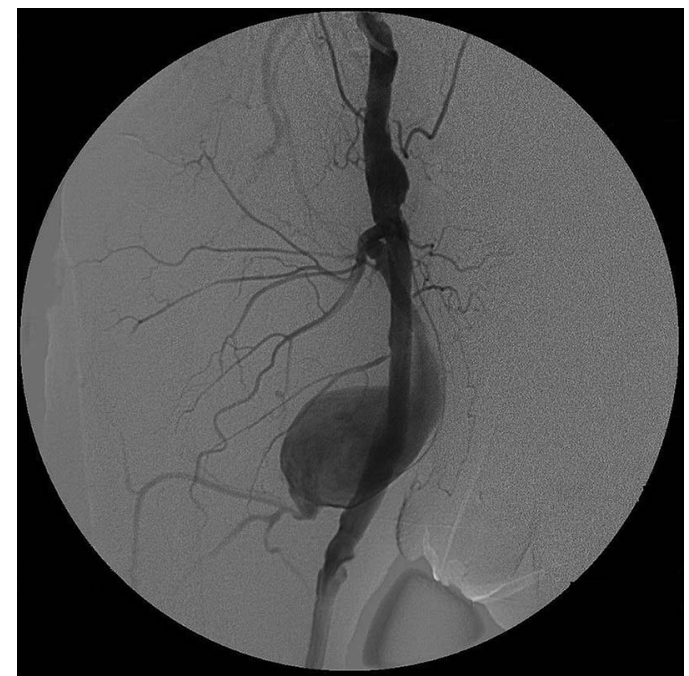

Figure 3 Pre-embolisation digital subtraction angiography showing a giant aneurysm originating in the deep femoral artery. 


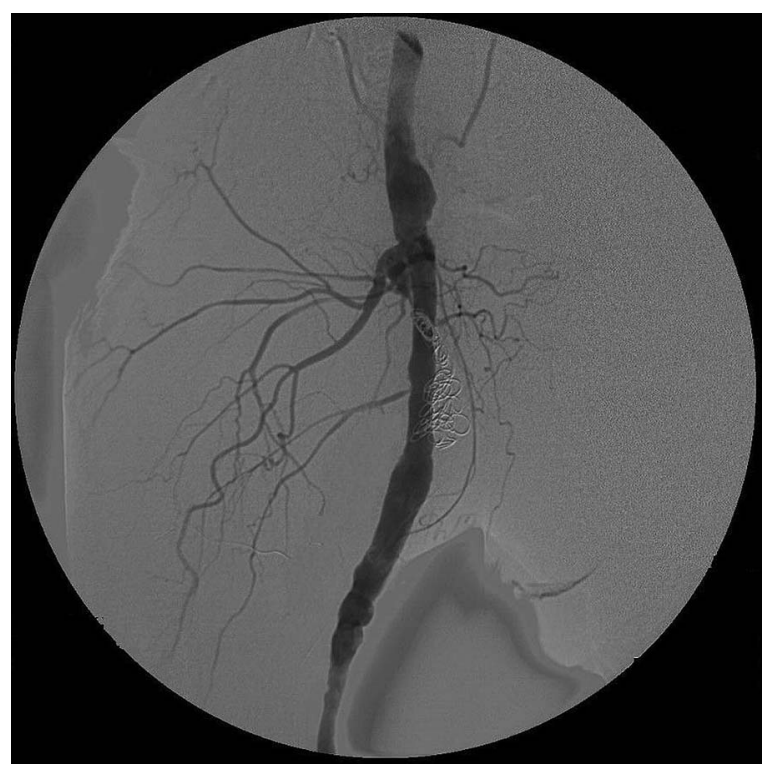

Figure 4 Postembolisation digital subtraction angiography showing absence of blood stream and availability of coils in the lumen of aneurysm.

diagnosis of a DFA aneurysm. The treatment for a DFA aneurysm is commonly surgical. ${ }^{3}$ If the patient cannot tolerate surgical repair, endovascular treatment may be a beneficial form of therapy. Three patients were treated with transcatheter coil embolisation in the literature. This method is less invasive than surgery and may be safe for patients with unstable cardiac function.

\section{Learning points}

- Deep femoral artery aneurysm is a rare vascular abnormality that may cause a variety of symptoms, such as ischaemia, venous stasis and peripheral atherosclerosis.

- Contrast-enhanced MR angiography or conventional angiography may be useful for diagnosis.

- Transcatheter coil embolisation is a less invasive treatment method in patients with unstable cardiac function.

Acknowledgements The authors thank Associate Professor Dr Orhan Özbek and Associate Professor Dr Osman Koc for their contribution in the treatment and management of the patient's care, and approval of the version to be published.

Competing interests None.

Patient consent Obtained.

Provenance and peer review Not commissioned; externally peer reviewed.

\section{REFERENCES}

1 Harbuzariu C, Duncan AA, Bower TC, et al. Profunda femoris artery aneurysms: association with aneurismal disease and limb ischemia. J Vasc Surg 2008; $47: 31-5$

2 Raine NMN, Wilensky J, Dimick J, et al. A true aneurysm of the profunda femoris artery: a case report and review of the English language literature. Ann Vasc Surg 2004;18:704-46.

3 Kawai N, Mori Y, Hatsune T, et al. Bilateral profunda femoris artery and left common femoral artery aneurysms presenting as lower limb ischemia. Ann Vasc Surg 2011;25:700.e5-7.

Copyright 2014 BMJ Publishing Group. All rights reserved. For permission to reuse any of this content visit http://group.bmj.com/group/rights-licensing/permissions.

BMJ Case Report Fellows may re-use this article for personal use and teaching without any further permission.

Become a Fellow of BMJ Case Reports today and you can:

- Submit as many cases as you like

- Enjoy fast sympathetic peer review and rapid publication of accepted articles

- Access all the published articles

- Re-use any of the published material for personal use and teaching without further permission

For information on Institutional Fellowships contact consortiasales@bmjgroup.com

Visit casereports.bmj.com for more articles like this and to become a Fellow 